\title{
Investigation of the Apparent Diseases of Urban Bridges in Shijiazhuang
}

\author{
Lipeng Wu, Peng Dai, Jinan Lu, Chongsheng Wu \\ School of civil engineering \\ Shijiazhuang Tiedao University \\ Shijiazhuang, China \\ lipengwu@outlook.com
}

\begin{abstract}
Reinforced concrete plays an important role in urban transport infrastructure. The durability of concrete bridges has caused wide public concern in many places of world. All the reinforced concrete bridges in Shijiazhuang's urban area were carefully investigated. Five diseases were detected: leak of alkaline substances, diaphragm defects, reinforcement corrosion, holes and pits in concrete and severely damaged barriers. Corresponding preventive measures were proposed. The disease types and their corresponding precautions may have a certain reference value for design and maintenance of reinforced concrete bridges in other northern China cities.
\end{abstract}

Keywords -concrete; durability; bridge; diseases; infrastructure

\section{INTRODUCTION}

Reinforced concrete bridge is the main form of urban bridges [1-3], and its durability has gradually received consid erable attention [4-12]. Durability survey can not only help bridge management and maintenance department fully understand the disease types and level, so corresponding measures can be taken, but also help design unit and construction unit raise awareness and both durability design standards and construction quality can be improved. The building sector is the largest energy and resources consumption industrial category, and is the largest carbon emitters too, so the achievement of durable bridges is critical for sustainable development. The bridges in the urban zone of Shijiazhuang are almost reinforced concrete bridges, and their apparent diseases can to some extent reflect the bridge diseases in northern China. A detailed investigation was conducted, and this paper will repo rt the findings.

\section{APPARENT DisEASES AND THEIR CAUSES}

\section{A. leak of alkaline substances}

The survey found that surface stains occurred at many bridges, and chemical analysis showed that the stains were co mposed of calcium carbonate (see Fig. 1). Alkali leaking may reduce the $\mathrm{pH}$ value of concrete pore solution, and may cause reinforcement depassivation leading to reinforcement corrosion, so both safety and durability levels may be reduced.

Surface stains were widely found near vent pipe joints and at the bottom surface of bridge decks and abutments. The direct cause of stains formation was water intrusion. Analysis showed that the reasons were: 1) blocked drain pipes; 2) too short extending length of drain pipes; 3) blocked expansion joint.

This work is supported by the Natural Science Foundation of Hebei, China (E2013210125) and Natural Science Foundation of China (51408379)

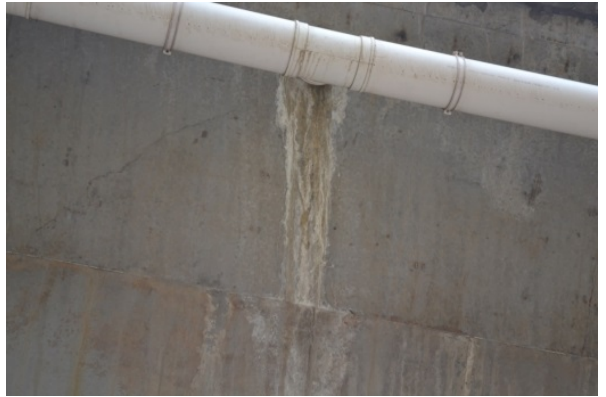

(a)

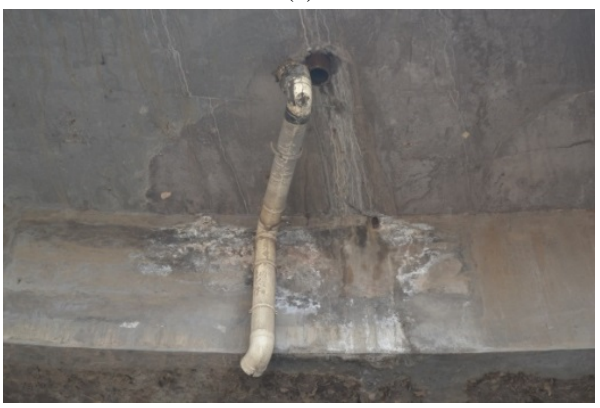

(b)

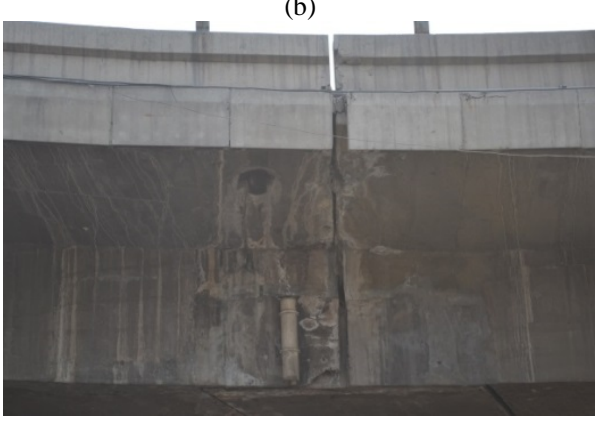

(c)

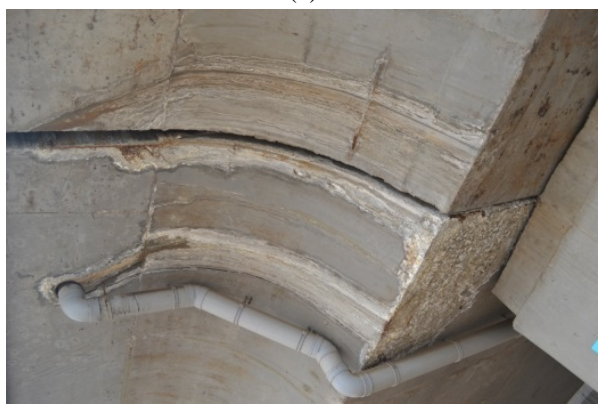

(d)

Fig. 1. leak of alkaline substances. 


\section{B. Diaphragm defects}

Precast T-beams are widely used in Shijiazhuang city's bridges, and due to design and construction reasons, there wer e many defects between $\mathrm{T}$ beams, see Fig. 2 for detail.

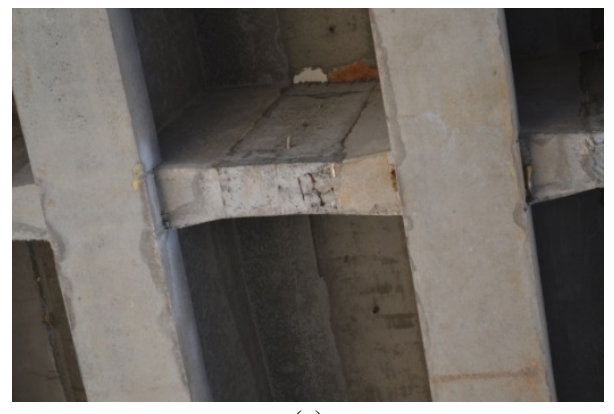

(a)

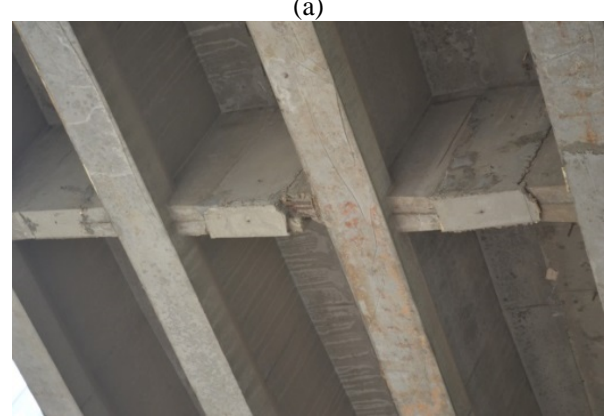

(b)

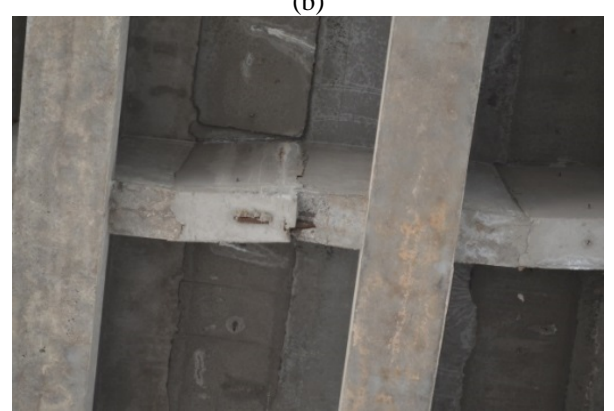

(c)

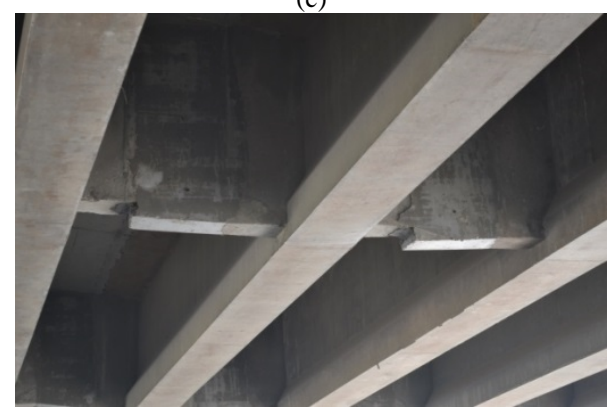

(d)

Fig. 2. diaphragm defects

Diaphragm defects can cause concrete cracking, steel corrosion and structural integrity loss, which are very adverse to seismic performance. The reasons for this phenomenon were: 1) diaphragm misalignment; 2) inconsistent upwards deflection after pre-stressing; 3) improper formwork installation.

\section{Reinforcement corrosion}

Uncovered rebars were found both in beams and plates (see Fig. 3). Exposed steel can easily be rusted and may hereafter cause concrete cover cracking and splitting, which may cause severe damage to durability.

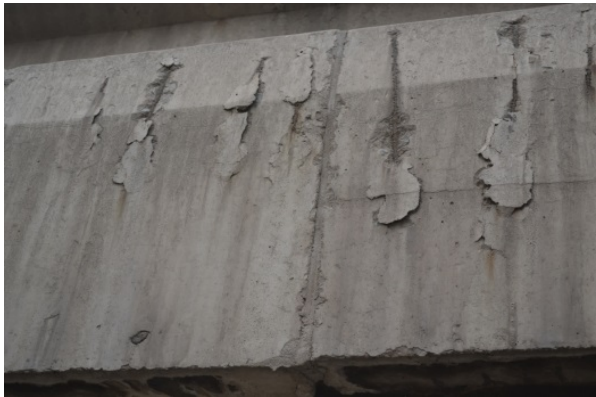

(a)

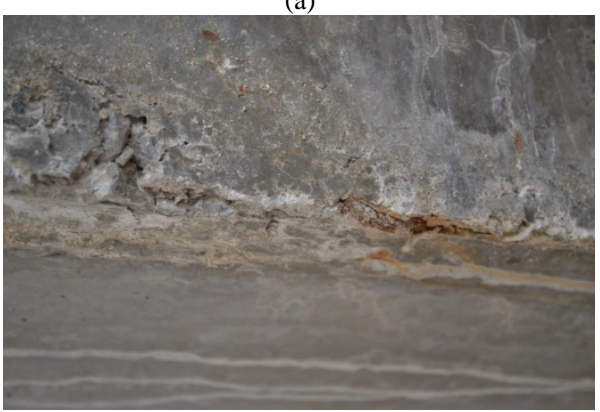

(b)

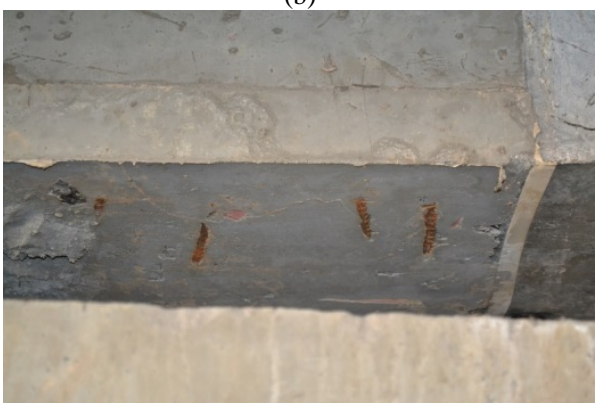

(c)

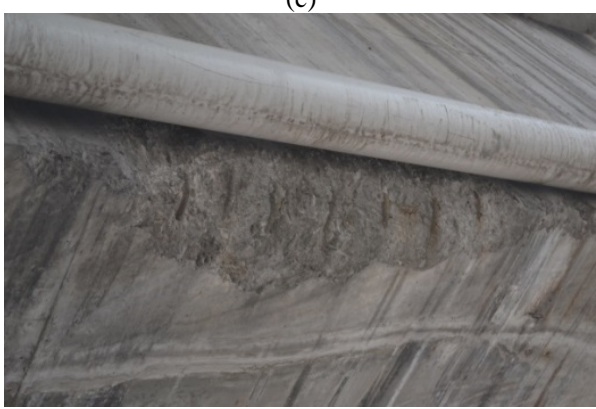

(d)

Fig. 3. Reinforcement corrosion

The above-mentioned disease was caused by: 1) insufficient concrete cover; 2) inappropriate vibrating; 3) vehicle collision; 4) concrete carbonation; 5) the use of de-icing salt.

\section{Holes and pits in concrete}

Holes and pits were found in many bridges, which means the concrete was not dense and its strength was lower than its design value (see Fig. 4). Oxygen, water, chloride ion and car- 
bon dioxide can penetrate into concrete more easily, which will accelerate concrete carbonation and steel corrosion rate. Service performance can be deteriorated, especially when exposed rebar exists.

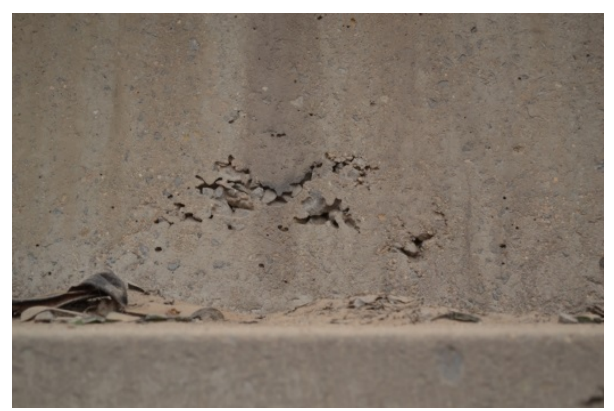

(a)

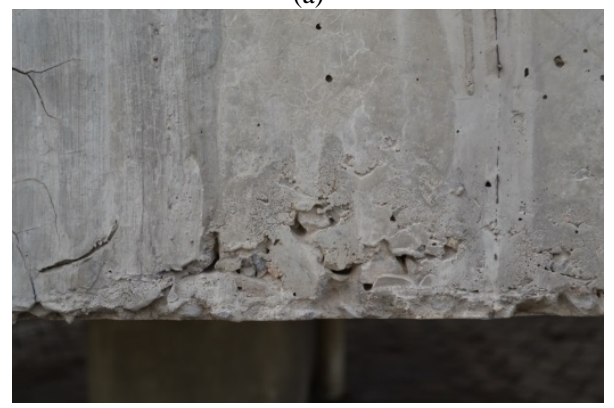

(b)

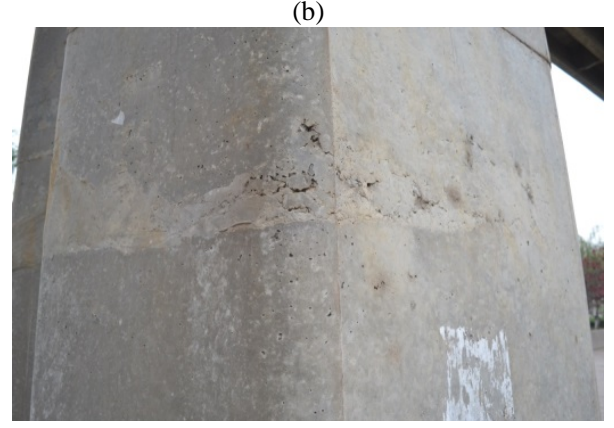

(c)

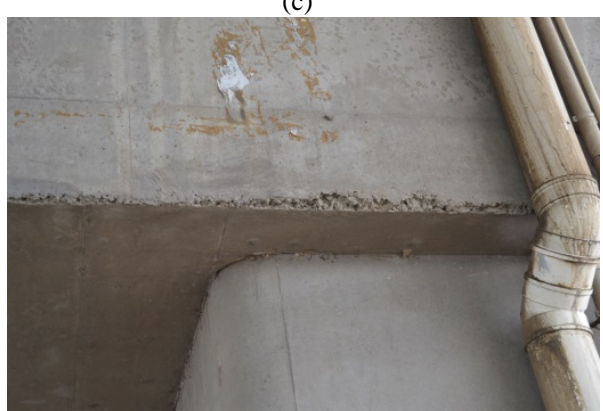

(d)

Fig. 4. Holes and pits

Possible reasons were: 1) poor workability of fresh concrete; 2) inappropriate concrete mix; 3) improper vibrating; 4) cement paste leakage; 5) insufficient concrete cover.

\section{E. Severely damaged concrete barrier}

In few cases, severely damaged concrete barriers, including pedestrian guardrails and safety barriers for vehicle, were observed, (see Fig. 5).

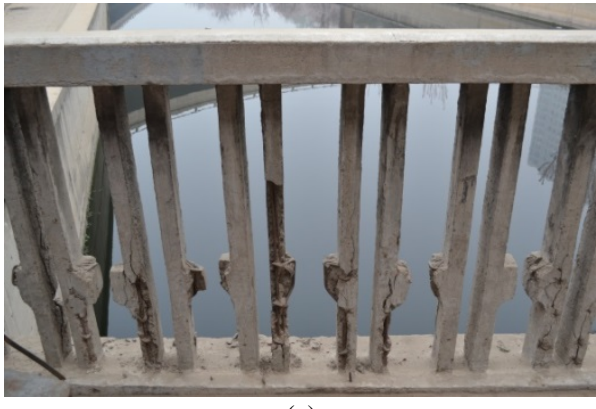

(a)

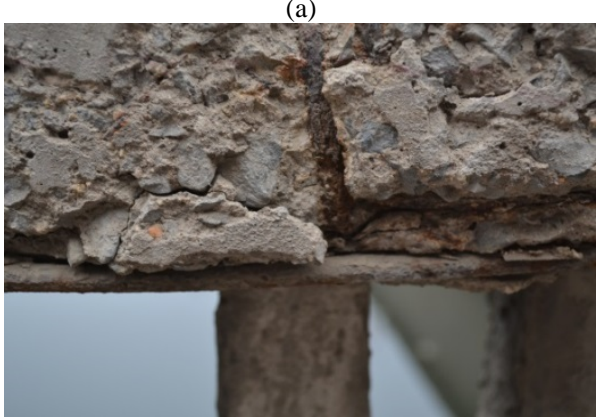

(b)

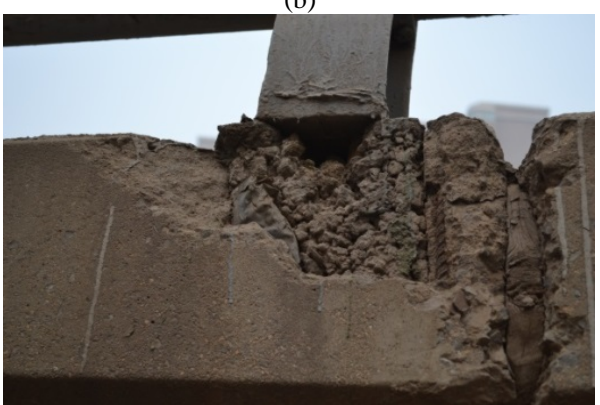

(c)

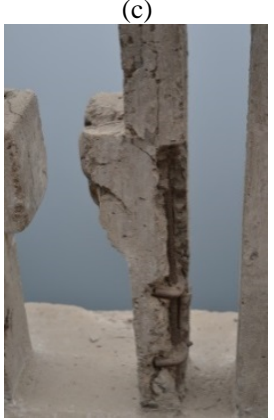

(d)

Fig. 5. Severely damaged barriers

The reasons for this disease were: 1 ) the use of de-icing salt; 2) incompact concrete; 3) vehicle collision; 4) improper rebar arrangement.

\section{PRECAUTIONS}

According to the survey results obtained, the following prevention measures were suggested.

1. Right concrete mix and appropriate additives should be used.

2. Effect of vibrating should be assured to get dense concrete. Controlled permeability formwork (CPF) and silane-based coatings may be utilized, if necessary. 
3. Pay attention to the design and the construction of drainage facilities to reduce the chance of harmful substances invasion.

4. Pay attention to transportation management and avoid vehicle collision.

5. Pay attention to daily maintenance to prevent further deterioration.

6. For some important bridge, use electrically conductive concrete instead of de-icing salt to melt ice.

\section{SUMMARY}

All the reinforced concrete bridges in Shijiazhuang's urban zone were carefully investigated. Survey results showed that the five main diseases were leak of alkaline substances, diaphragm defects of T-shaped beams, reinforcement corrosion, holes and pits in concrete and severely damaged roadside barriers. According to survey results, the main reasons of each disease were found out, and six preventive measures were proposed.

\section{REFERENCES}

[1] S. Wakchaure, K.M. Jha, "Review of inspection practices, health indices, and condition states for concrete bridges", Indian Concrete J. vol. 86, no 3, pp. 13-26, March 2012.

[2] Y.J. Yoon, and M. Hastak, Review of MR\&R activities for concrete bridge decks in the U.S. Life-Cycle of Structural Systems: Design, Assessment, Maintenance, and Management - Proceedings of the 4th International Symposium on Life-Cycle Civil Engineering, IALCCE 2014, pp. 854-861, 2015.

[3] Z. Liu, Zhao. "Historical review and development concern of concrete bridges”, Bridge Constr. vol. 43, no. 5, pp. 5-11, October 2013.

[4] M.L. Berndt, and P.A. Shaw, "Durability planning for concrete on the Ross River Bridge, Townsville”, Australian J. Civil Eng. vol. 10, no. 2, pp. 99-115, 2012.

[5] A.R. Chen, S.R. Feng, and R.J. Ma, "Environmental zoning for durability performance of concrete bridges based on deterioration mechanism”, J. Tongji University, vol. 42, no. 3, pp. 331-337, March 2014.

[6] R. Nidiffer, E. Burdette, C. Brown, and R. Ankabrandt, "Efficacy of a ternary blend mixture in improving bridge deck concrete durability in Tennessee”, J. Mater. Civil Eng. vol. 26, no. 10, 2014.

[7] M. Bian, Q. Bai, Y. M. Kang, J. Zhang, "A Review of Durability Research of Concrete Bridge", Appl. Mech. Mater. vols. 423-426, pp. 1132-1136, Sep. 2013.

[8] H.C. Wu, and A. Yan, "Durability simulation of FRP bridge decks subject to weathering.” Compos. Part B-Eng. vol. 51, pp. 162-168, 2013.

[9] W.D. Lindquist, D. Darwin, J. Browning, and G.G. Miller, "Effect of cracking on chloride content in concrete bridge decks.” ACI Mater. J., vol. 103, no. 6, pp. 467-473, 2006.
[10] K.H. Obla, "Specifying fly ash for use in concrete.” Concr. In Focus, vol. 7, no. 1, pp. 60-66, 2008.

[11] E. Ryan, E. Burdette, R. Ankabrandt, R. Nidiffer, and B. Buchanan, "Comparison of two methods to assess the resistance of concrete to chloride ion penetration.” J. Mater. Civ. Eng., 10.1061/(ASCE) MT.1943-5533.0000844, vol. 26, no. 4, pp. 698-704, 2014.

[12] AASHTO. "Standard method of test for surface resistivity indication of concrete's ability to resist chloride ion penetration.” AASHTO TP 9511, Washington, DC, 2011. 